\title{
The Research of Tank Sides Geometrical Forms after their Long-Term Usage in the Oil Transportation System
}

\author{
Alexey Pimnev ${ }^{1}$, Svetlana Ivantsova ${ }^{2}$, Ruslan Aginey ${ }^{3}$, and Tatyana Ponomareva ${ }^{4, *}$ \\ 1,4 Industrial University of Tyumen, 625001, Volodarskogo str., 38, Tyumen, Russia \\ ${ }^{2}$ Gubkin Russian State University of Oil and Gas, Leninsky prospekt 65, Moscow, Russia \\ ${ }^{3}$ JSC “Giprogazcentr", st. Alexeevskaya 26, Nizhniy Novgorod, Tyumen, Russia
}

\begin{abstract}
During the technical diagnosis of vertical steel tanks it is necessary to evaluate the influence of geometry imperfection on deflected mode and resource. One of the most significant characteristics of geometry, definable during the full-scale tank diagnosis, is deflections of tank generatrices from the vertical. In the report, the tank geometry research results are represented on the basis of measuring data of 98 oil transporting system tanks
\end{abstract}

\section{Introduction}

The existing tank battery in a system of oil transportation is considerably depreciating. In recent years, the scope of repair, reconstruction, and construction of new storage tanks. It predetermined the increase of scope of technical diagnosis of vertical steel tanks (VST) with attraction of new technical means and methods. VST technical condition's estimation problem can be solved by using two-level technical diagnostics system, whereby frequency and type of inspections depends on the working service. However, the existing system of technical diagnostics reflects modern requirements not to the full [1-8].

In these conditions, it is necessary to take measures increasing the effectiveness of tanks usage by means of extension their safe working service in the process of production [9-13]. As vertical steel tanks are elements of complicated technical systems of extraction, transportation, and storage of oil and oil products, reliability assurance and estimation of safe working service of functional tanks is specifically connected with lifetime improvement of tank battery and all the system of pipeline transport. Besides that, the consequence of reliability enhancement is safety of main funds.

The problem of the reliability of tanks is connected with issues of reduction losses of oil and oil products as a result of leaks and accidents, as well as poor technical condition of a tank shall and bottom. Financial losses in tanks accidents are large and tend to increase due to the increase in reservoir capacity. At the same time, due to numerous indirect expenses, the real damage is higher than direct losses at recovery and the cost of production. Even the

\footnotetext{
Corresponding author: feldmarshal@,inbox.ru
} 
costs of the fight against environmental pollution caused by leakage of products are higher than direct losses in more than several times.

The problem of estimation of technical condition of vertical steel tanks after long operation service can be solved by using technical diagnostics system. When diagnosing the technical condition of the VST after long-time operation service, we should take into account manufacturing experience in complex tanks surveys during which special attention should be paid to changes in the geometric shape that can occur in the state and operating conditions of the tank batteries of oil pipelines trunks.

\section{The object of research}

The imperfections of the tank geometric shape leads to significant changes in the stresseddeformed state under the influence of operating loads. Domestic and foreign manufacturing experience enables us to conclude that most of the accident occurs due to rupture of metal structures of the tank. If there are deformations in the areas of welded seams of the wall, the destruction probability increases. Experimental studies carried out on cylindrical shells shown that even a small deviation from the ideal shape leads to a decrease of the critical load. Therefore, we can conclude that the geometrical shape imperfections result in reduced operational reliability of the tank.

Analysis of the geometric shape of the wall of steel vertical cylindrical tanks was made based on the results of field technical diagnosis [8]. As the basis, the deviations of measuring data of 98 oil transporting system tanks. The distribution of the measurements of deviations of tank generatrices from the vertical for different typical sizes of tanks is shown in Figure1.

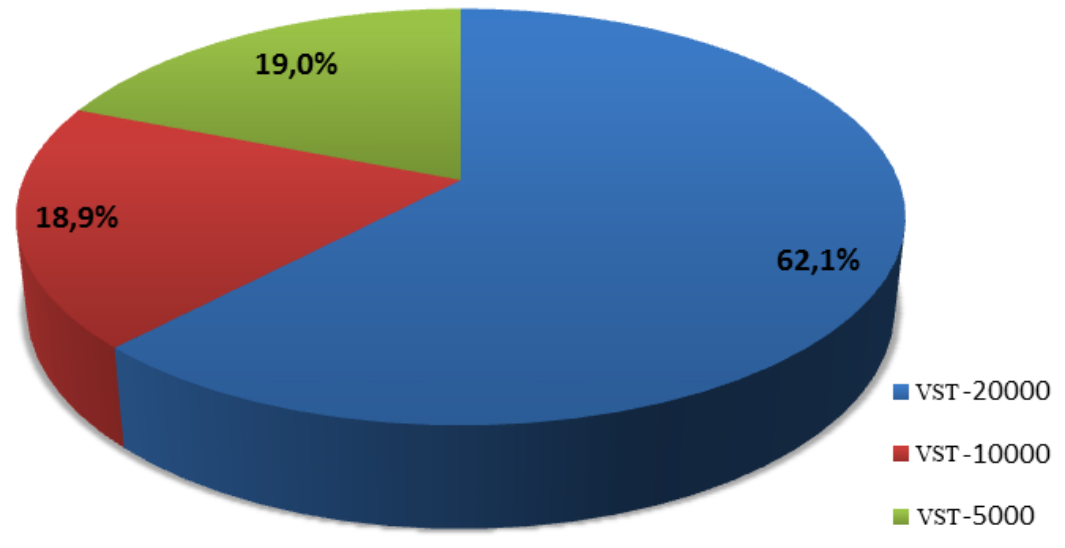

Fig. 1. The distribution of studied tanks by standard sizes

\section{Methods}

Vertical steel tanks have a cylindrical shape, the geometric dimensions of which are determined by deviations of the tank generatrices from the vertical. During the operation, change of the geometric shape of the tank often occurs due to uneven subsidence of the bottom caused by poor preparation of the base, under the influence of vacuum, hydrostatic load, vibration or overflow.

Measurement of geometric forms of tanks walls was carried out by means of direct measurement of deviations of the tank generatrices from the vertical using the highly 
accurate theodolite and devices developed at the "Construction of oil and gas pipelines," Department of the Tyumen Industrial Institute (AS.: authors Tarasenko A.A., Galeev V.B., Leshchev N.N.) by the method described in [1].

Goniometer is placed at a tangent to the generatrix at a distance of 20 to 40 meters. From one location of a device, shooting of deviation of maximum two generatrices was made. Depending on the typical size and structural features of tanks, measuring was carried at 24 or 25 generatrices for VST-20000, 18 - for VST -10000 and 12 - for VST-5000. Measurements for each zone, from the $1 \mathrm{st}$ to the $8 \mathrm{th}$, were made at points $50 \mathrm{~mm}$ below the top horizontal seam of the corresponding zone, as required by current regulatory documentation for diagnostics and maintenance of tanks.

In total, with the participation of the author, 1846 deviations of the tank generatrices from the vertical were measured, which required 14768 measurements. For the analysis, all the measurements were divided into groups depending on the typical sizes and terms of operation of tanks (table 1).

For different typical sizes of tanks, the amount of field joints is equal to the number of rolls, of which the tank side is produced. Thus, for the construction of the VST-5000 one roll is used, that is closed by a vertical field joint, for VST-10000, 2 rolls and 2 field joints respectively, for VST-20000 - 3 vertical field joints. Therefore, the percentage of field joints of tank sides is constant and depends on the typical size of the tank:

- for VST-20000 is $12.5 \%$;

- for VST-10000 is $11.1 \%$;

- for VST-5000 is $8.3 \%$.

Table 1. The number of completed measurements of generatrix deviations from the vertical and distribution by their size and the terms of operation

\begin{tabular}{lcccc}
\hline \multirow{2}{*}{ Terms of operation } & \multicolumn{3}{c}{ Typical size of the tank } & \multirow{2}{*}{ Total } \\
\cline { 2 - 4 } & VST-20000 & VST-10000 & VST-5000 & \\
\hline Up to 20 years & $461(25.0 \%)$ & 0 & $201(10.9 \%)$ & $662(35.9 \%)$ \\
Over 20 years & $686(37.1 \%)$ & $349(18.9 \%)$ & $149(8.1 \%)$ & $1184(64.1 \%)$ \\
Total & $1147(62.1 \%)$ & $349(18.9 \%)$ & $350(19.0 \%)$ & $1846(100 \%)$ \\
\hline
\end{tabular}

Table 2 shows the number and percentage of the generatrices, accounted for by the factory and field joints of a tank side. Minor deviations from the theoretical values of field joints of tank sides, defined above, are explained by the inability, in many cases, to make all generatrices measurements because of the presence of the structural elements on the tank side (servicing areas, pipes, stairways, etc.) at the junctions of the tank sides. 
Table 2. Percentage of factory and field joints in measurements of generatrices deviations from the vertical

\begin{tabular}{llccc}
\hline \multirow{2}{*}{\begin{tabular}{c} 
Typical size of $\begin{array}{c}\text { Terms of } \\
\text { the tank }\end{array}$ \\
\cline { 2 - 4 }
\end{tabular}} & $\begin{array}{c}\text { Termeration } \\
\text { opery }\end{array}$ & Total & \multicolumn{3}{c}{ incl. joints seams, p. [\%] } \\
\cline { 3 - 5 } VST-20000 & Up to 20 years & 461 & $404(87.6 \%)$ & $57(12.4 \%)$ \\
& Over 20 years & 686 & $600(87.5 \%)$ & $86(12.5 \%)$ \\
& Total & 1147 & $1004(87.5 \%)$ & $143(12.5 \%)$ \\
\hline \multirow{3}{*}{ VST-10000 } & Up to 20 years & 0 & 0 & 0 \\
& Over 20 years & 349 & $309(88.5 \%)$ & $40(11.5 \%)$ \\
& Total & 349 & $309(88.5 \%)$ & $40(11.5 \%)$ \\
\hline \multirow{2}{*}{ VST-5000 } & Up to 20 years & 201 & $184(91.5 \%)$ & $17(8.5 \%)$ \\
& Over 20 years & 149 & $136(91.3 \%)$ & $13(8.7 \%)$ \\
& Total & 350 & $320(91.4 \%)$ & $30(8.6 \%)$ \\
\hline
\end{tabular}

In order to avoid errors and biases in the analysis of the results of measurements deviations of the generatrices, the problem of the representation aggregate sample the obtained values was solved, and interrelation of between the measurement point and the value of the deviations at that point which could be obtained in the study of aggregation was established [16,20].

Since the considered sample is big enough, a hypothesis was advanced that the measured set of random values is subject to a normal distribution law. However, for the final decision on the form of the distribution law, it seems appropriate to check whether this assumption is consistent with reality. At the same time, due to the limited number of observations, an experienced distribution law, even if the assumption about the distribution law is done correctly will still be slightly different from the expected. In this regard, it was necessary to determine: whether the discrepancy between the experimental and anticipated distribution law is a consequence of the limited number of observations or it is significant and connected to the fact that the actual distribution of the random variable is different from the intended.

To verify compliance with the random variable distribution deviations form the wall of the normal distribution law, verification was carried out by one of the most common and important in mathematical statistics fitting criteria - $\chi^{2}$ goodness of fit test. As an example, a random variable of deviations of geneatrix for the 8th zone of side of VST-20000, which varies from minus 214 to 268 is considered in [8].

As a result of calculations, it was revealed that the discrepancy between the theoretical distribution law and the law, built on the basis of statistical data is irrelevant, accidental, suggesting that the observed value of the test for the 8th zone of tank side of VST-20000 is subject to the normal distribution law. This hypothesis is confirmed for other zones, i.e. in all cases it is subject to the normal distribution law.

For below mentioned groups of tanks, distribution curves of deviation values of generatrices were built at belts. The obtained data were processed by the method described in researches $[1,2]$. Axis of abscissas shows the values of deviations form the wall: the outside (positive values) - to the right, the inside (negative values) - to the left, the vertical axis - the accumulated relative frequency of deviations $\Sigma \omega$. Separate frequencies are proportions of the corresponding ranges of values of the measured deviations of generatrices of their total number in this zone.

Connecting each zone accumulated relative frequencies $(\Sigma \omega=0.5)$ to each other, we get the midline, around which there is a change of values of generatrices. This line is a 
correlation curve between the height of the body and the point value deviations of generatrices (Figure 2).

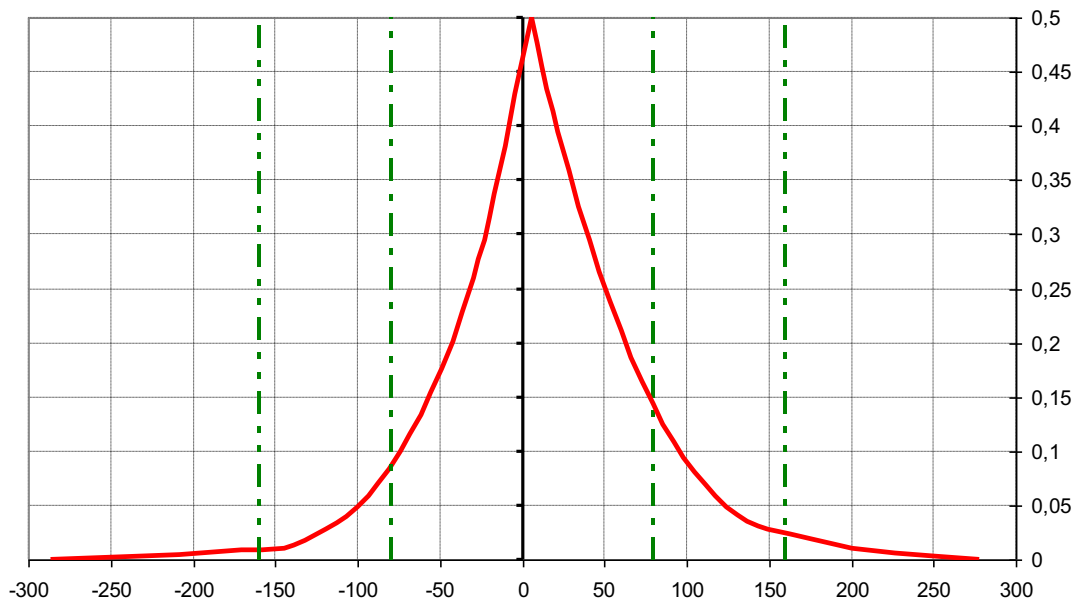

Fig. 2. The distribution curve of generatrices deviations

Analysis of the distribution of values of generatrices deviations of the VST-20000 zones showed that the probability of unacceptable deviations is different at different levels (Figure 3). Analysis of the dependence of the probability of occurrence of unacceptable deviations from the measurement place indicates that maximum probability corresponds to the level of the first zone and is $43 \%$, then it gradually decreases, reaching a minimum at the level of 6-7th zones (18\%), and increases again at the level of the 8 th zone to $22 \%$. Thus, special attention in the imperfections of geometric shapes of wall evaluation must be paid to the measurements on the first three and the last zone of the tank.

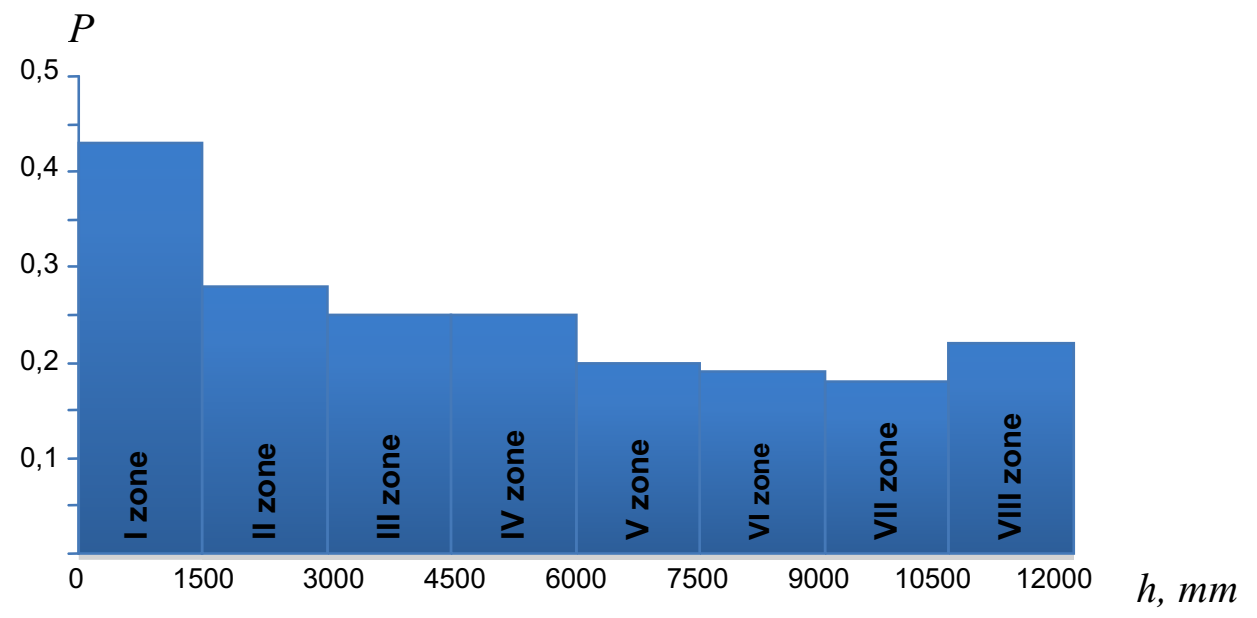

Fig. 3. The dependence of the probability of occurrence of unacceptable deviations on shell height

According to the results of the statistical analysis of deviations measurement data of the generatrices from the vertical, the dependence of the probability of occurrence of unacceptable deviations in height of the shell is obtained. The dispersion coefficient of the approximating curve is 0.91 : 


$$
p(h)=\left(4 \cdot 10^{-9}\right) h^{2}-\left(7 \cdot 10^{-5}\right) h+0,5
$$

Having interconnected points of the curves for all zones with the accumulated relative frequencies $(\Sigma \omega=0)$ and $(\Sigma \omega=1)$, we obtained left and right variation limits of generatrices deviations. The probability of getting the value generatrices deviations in a region bounded by these curves is equal to 1 .

If we correspondingly interconnect points of with the accumulated relative frequencies $\Sigma \omega=0,1$ and 0,$9 ; \Sigma \omega=0,2$ and 0,$8 ; \Sigma \omega=0,3$ and $0.7 ; \Sigma \omega=0,4$ and 0.6 , we obtain the areas with a probability of getting the generatrices deviations into them, which are equal to: $\mathrm{F}=$ $0.8 ; \mathrm{P}=0.6 ; \mathrm{P}=0.4 ; \mathrm{P}=0.2$, respectively. Thereby, we obtain the tank wall generatrices deviations, depending on the capacity of the tank.

Table 3. Comparing the characteristics of the studied tanks to tolerance deviations of generatrices from the vertical.

\begin{tabular}{lcccc}
\hline \multirow{2}{*}{ № of zone } & \multicolumn{2}{c}{$\begin{array}{c}\text { Acceptable deviations with term } \\
\text { of operation over } 20 \text { years }[\mathrm{mm}]\end{array}$} & \multicolumn{2}{c}{$\begin{array}{c}\text { Generatrix deviations with } \\
\text { probability } \mathrm{P}=1 \text { [mm] }\end{array}$} \\
\cline { 2 - 5 } & $\begin{array}{c}\text { for } 75 \% \\
\text { generatrices }\end{array}$ & $\begin{array}{c}\text { for } 25 \% \\
\text { generatrices }\end{array}$ & Inside the tank & $\begin{array}{c}\text { Outside the } \\
\text { tank }\end{array}$ \\
\hline I & 40 & 52 & 74 & 95 \\
II & 60 & 78 & 125 & 130 \\
III & 80 & 104 & 157 & 165 \\
IV & 100 & 130 & 220 & 205 \\
V & 120 & 156 & 225 & 205 \\
VI & 140 & 182 & 205 & 210 \\
VII & 150 & 195 & 248 & 250 \\
VIII & 160 & 208 & 270 & 268 \\
\hline
\end{tabular}

The tolerance limit of deviations of the steel generatrices of the tanks of type VST20000 from the project verticals should not exceed the values in accordance with the requirements of the current regulatory documentation. In table 3 shows a comparison of characteristics of the studied tanks to the requirements of regulatory documents.

Comparing the data from the survey of tanks to regulatory requirements, it can be concluded that the area of actual values of generatrix deviations goes beyond the area of acceptable values. Thus, the tanks were operated at project conditions with term of operation longer than the standard one in $65 \%$ of surveyed of tanks. Therefore, the requirements of the current regulatory documentation can be regarded as overstated, and it is necessary to reconsider the approach to the evaluation of the residual operation life, on the criterion of geometrical shapes, in particular.

In studies [3-7], a method of monitoring the forecasting of indicators of reliability and supplying the transition from "afterfailure" system of service and repair to a "preventive" one on predictive indices of reliability of pipeline transport. Analyzing the abovementioned, we can conclude the necessity of solving problems of estimation the technical state of each tank in accordance with its technical condition [21,22].

\section{Results and discussion}

Analyzing the distribution curves of the values of generatrix deviations, we can conclude the following:

1. The value of generatrix deviations grows with an increase in height and decrease in the plate thickness of the shell, and this quantity is mostly distributed over a sinusoidal curve. 
2. The middle line, around which the value variation of generatrix deviations takes place, is not located in a vertical plane passing through the outer surface of the cylindrical shell, but stands outside of the tank.

3. The largest in absolute magnitude generatrix deviations are observed on the outside face of the tank side.

\section{Conclusion}

It was found that the maximum probability of unacceptable generatrix deviations corresponds to the level of the first zone and makes up 43\%, then it gradually decreases, reaching a minimum at 6-7 zones (18\%), and increases again at the level of 8 to $22 \%$ zone. Thus, to improve the estimation accuracy of tank side geometric shapes imperfections, it is necessary for the first three and the last zones to increase the density of measurement grid.

The middle line, around which there is the variation of values of generatrix deviations, is not situated in a vertical plane passing through the outer surface of the cylindrical shell, but stands out of a tank. Thus the greatest in absolute magnitude generatrix deviation can be observed at the outer side of the tank.

\section{References}

1. A. Tarasenko, Deflected mode of tanks during repair works (Nedra, Moscow, 1999)

2. G. Hopersky, Thesis of Candidate of Technical Sciences (TSOGU, Tyumen, 1998)

3. M. Zemenkova, Thesis of Candidate of Technical Sciences (TSOGU, Tyumen, 2007)

4. V. Kurushina, Yu. Zemenkov, WIT Transactions on Ecology and the Environment, 190(2), 881-888 (2014)

5. V. Antip'ev, A. Nevolin, Yu. Zemenkov, Neftyanoe Khozyaistvo - Oil Industry, 10, 46-48 (1981)

6. Yu. Zemenkov, V. Shalay, M. Zemenkova, Procedia Engineering, 113, 254-258 (2015)

7. Yu. Zemenkov, V. Shalay, M. Zemenkova, Procedia Engineering, 113, 312-315 (2015)

8. A. Pimnev, Thesis of Candidate of Technical Sciences (TSOGU, Tyumen, 2006)

9. E. Kurushina, V. Kurushina, Life Science Journal, 11(11), 517-521 (2014)

10. V. Kurushina, Yu. Zemenkov, E. Kurushina, Fundamental researches, 2-8, 1632-1636 (2015)

11. E. Kurushina, Canadian Journal of Science, Education and Culture, 2(6), 378-384 (2014)

12. E. Kurushina, Problems of formation of a common economic space and social development in the CIS countries: Proceedings of the International scientific and practical conference, 27-33 (2011)

13. S. Toropov, Yu. Zemenkov, S. Podorozhnikov, Gas industry, 720(720), 95-98 (2015)

14. M. Zemenkova, L. Fayzulina, I. Seroshtanov, Gas industry, 720(720), 59-64 (2015)

15. R. Mamadaliev, V. Kuskov, Yu. Zemenkov, A. Applied Mechanics and Materials, 770, 19-22 (2015)

16. A. Shabarov, A. Ibragimov, M. Zemenkova, S. Podorozhnikov, Gas industry, 12(715), 50-54 (2014)

17. A. Pimnev, M. Zemenkova, Pipeline transport: theory and practice, 5(51), 43-47 (2015)

18. M. Zemenkova, Yu. Zemenkov, A. Pimnev, V. Petryakov, Business magazine Neftegaz.RU, 11-12, 64-70 (2015)

19. A. Pimnev, M. Zemenkova, Fundamental researches, 11-2, 292-296 (2015) 
20. S. Stepanov, N., Cheremisin, S., Sokolov, A., Altunin, A., Shabarov, Computational method for relative permeability curves based on the Bernoulli generalized porous media equations, ECMOR 2012 - 13th European Conference on the Mathematics of Oil Recovery. (2012)DOI: 10.399/2214-4609.20143270.

21. R. Levitin, Yu. Zemenkov, Neftyanoe khozyaystvo - Oil Industry, 1, 110-114 (2016)

22. Ya. Gorelik, A. Shabarov, Yu. Sysoyev, Earth's Cryosphere, 12(1), 59 (2008) 